\title{
The influence of competition from herbaceous vegetation and shade on simulated browsing tolerance of coniferous and deciduous saplings
}

\author{
Charlotte Vandenberghe, François Freléchoux and Alexandre Buttler
}

C.Vandenberghe (c.vandenberghe@macaulay.ac.uk), F. Freléchoux and A. Buttler, Swiss Federal Research Inst., WSL Station 2, EPFL, CH-1015 Lausanne, Switzerland. Present address for CV: The Macaulay Land Use Research Inst., Craigiebuckler, Aberdeen, Scotland, AB15 8QH. AB also at: Laboratory of Ecological Systems ECOS, Ecole Polytechnique Fédérale de Lausanne EPFL, Station 2, CH-1015 Lausanne, Switzerland.

\begin{abstract}
The ability of saplings to tolerate browsing (i.e. the ability to persist with reduced biomass and to compensate for biomass loss) is influenced by the level of stress and their growth strategies. Ultimately, insight into species-specific responses of saplings to browsing, shade and competition from neighbours will help explain diversity, structure and function of grazed ecosystems such as the endangered wood-pasture systems. We measured the survival, whole-sapling biomass and compensatory growth responses of two coniferous (Picea abies and Abies alba) and two deciduous (Acer pseudoplatanus and Fagus sylvatica) tree species to simulated summer browsing (one single clipping event), shade (installation of a shade cloth) and neighbour removal (mowing surrounding vegetation to ground level) treatments and the interactions between them after two-growing seasons. For all species, there were interacting effects on growth of browsing and environmental condition (shade and neighbours). Simulated browsing resulted in relatively smaller growth losses when plants were growing slowly due to competitive conditions related to herbaceous neighbours. Although none of the clipped saplings could fully compensate for their biomass losses, the saplings were closer to compensation under high competitive conditions than under low competitive conditions. Survival of the clipped saplings remained relatively high and was only significantly reduced for Picea and Acer. Picea was least tolerant of competition and was the only species for which growth was not negatively affected by strong irradiance of a mountain pasture. Surprisingly, the tolerance of saplings to herbivory as browsing tolerance was enhanced under conditions that negatively affected sapling performance (i.e. survival and growth). Apparently, the relative impact of browsing at the early sapling stage is linked to tree life history characteristics such as competition and shade tolerance and will be lower in situations with intense competitive interactions and/or strong irradiance.
\end{abstract}

Tree sapling survival and growth in grazed ecosystems such as wood-pastures is often negatively influenced by summer browsing disturbance from cattle (Bakker et al. 2004, Smit et al. 2006, Vandenberghe et al. 2007). The ability of saplings to tolerate browsing depends predominantly on the capacity to persist with reduced biomass and the ability to compensate for biomass loss through active regrowth (Haukioja and Koricheva 2000). Tolerance to herbivory is primarily determined by intrinsic factors that are genetically and/or developmentally determined by the plant itself (Rosenthal and Kotanen 1994, Strauss and Agrawal 1999). Compensatory growth responses are considered to be less developed for coniferous species because fastgrowing deciduous species have more flexible growth patterns and can profit from their ability to mobilize stored energy reserves from stems and roots for refoliation (Bryant et al. 1983, Ayres et al. 2004, Hester et al. 2004). However, saplings in wood-pasture systems are not exposed solely to browsing, but to several environmental factors simulta- neously (House et al. 2003). Consequently, browsing tolerance is also affected by the level of stress imposed by extrinsic factors (Rosenthal and Kotanen 1994) such as shade (e.g. from adult trees) and competition from surrounding herbaceous neighbours. It is commonly assumed that plants have a greater tolerance to herbivory when growing in low-stress, resource-rich environments (i.e. compensatory continuum hypothesis, Belsky et al. 1993, Hjälten et al. 1993). However, controversy exists concerning the compensatory continuum hypothesis and (over)compensation might also occur under high stress conditions (Hawkes and Sullivan 2001, Wise and Abrahamson 2005). In general, shade and competition from surrounding neighbours reduce sapling performance (i.e. survival and growth) (Kozlowski and Pallardy 1997, Peltzer and Köchy 2001, Pagès et al. 2003) and, as consistent with the compensatory continuum hypothesis, might reduce browsing tolerance (McLaren 1996, Weltzin et al. 1998, Blundell and Peart 2001). However, sapling performance 
may also improve under shade, due to direct effects on physiology (e.g. photosynthesis and transpiration) (Callaway 1992, Alves et al. 2002) or due to indirect effects such as competitive release of herbaceous species (i.e. indirect facilitation, Levine 1999, Siemann and Rogers 2003). Furthermore, neighbourhood vegetation might increase sapling performance by providing shade and moisture or protection against predators (Gill and Marks 1991). Hence, it is important to define low- and high-stress environments and the level of resource availability that plants may be adapted to prior to investigating tolerance responses.

Wood-pastures are highly biodiverse systems in which large herbivores drive vegetation dynamics through the maintenance of complex assemblages of grassland, shrub and woodland patches (Olff et al. 1999, Bakker et al. 2004, Smit et al. 2006). The origin of wood-pasture systems is debated: Pott and Hüppe (1991) postulate such systems were shaped by humans through extensive grazing by domesticated animals and logging since Neolithic time, but others suggest a natural origin by now extinct large grazers (Vera 2000). In recent decades, agricultural intensification or abandonment has reduced the area occupied by ancient wood-pastures. Land managers and ecologists are increasingly interested in conserving and restoring woodpasture systems to preserve biodiversity and provide socioeconomically options for local farmers (Etienne 1996). In the remaining wood-pastures of the Swiss Jura Mountains, two coniferous (Abies alba and Picea abies) and two deciduous tree species (Acer pseudoplatanus and Fagus sylvatica) co-occur. These tree species have different growth strategies (Breziecki and Kienast 1984, Ammer 1996, Pagès et al. 2003) and insight into the species-specific responses of the saplings to browsing, shade and competition from neighbours will help explain the community composition dynamics of the endangered wood-pasture systems (Liang and Seagle 2002, House et al. 2003).

The overall aim of our study was to determine the interactions between simulated browsing tolerance and different environmental factors for four co-occurring tree species. We measured the survival, whole-sapling biomass and compensatory growth responses of two coniferous and two deciduous tree species to simulated summer browsing, shade and neighbour removal (mowing) treatments and the interactions between them. We addressed the following specific questions: 1) how do shade and competition from neighbours affect tree sapling performance? 2) Is the tolerance of saplings to simulated browsing (in terms of survival and growth) positively or negatively affected by the level of stress imposed by shade and competition from neighbours? 3) Does tolerance to simulated browsing (in terms of survival and growth) differ between the four tree species?

\section{Material and methods}

\section{Study site and species}

The experiment was set up in a calcareous grass-sown sward, situated in the wood-pastures of the Swiss Jura Mountains (La Frétaz, Bullet, 6 $34^{\prime} 30^{\prime \prime} \mathrm{E}, 46^{\circ} 50^{\prime} 30^{\prime \prime} \mathrm{N}, 1200 \mathrm{~m}$ a.s.l.). The most common species in the sward were Dactylis glomerata, Phleum pratense, Taraxacum officinale, Lolium perenne and Agrostis capillaris (nomenclature follows Lauber and Wagner 2000). Prior to the experiment the sward was mown and cattle were excluded. The mean July temperature in 2004 and 2005 was $13.8^{\circ} \mathrm{C}( \pm 3.7 \mathrm{SD})$ and $14.7^{\circ} \mathrm{C}$ $( \pm 4.1 \mathrm{SD})$ respectively. Total precipitation in 2004 and 2005 was $1374 \mathrm{~mm}$ and $1036 \mathrm{~mm}$ respectively. Rock fragments in subsurface soil were present. To decrease the vole population (mainly Arvicola terrestris) an exclosure consisting of chicken mesh was constructed $0.5 \mathrm{~m}$ above and below ground level and voles were captured with traps within the exclosure to reduce predation of the saplings.

Saplings of Picea abies, Abies alba, Acer pseudoplatanus and Fagus sylvatica (hereafter referred to as Picea, Abies, Acer and Fagus respectively), selected by size, were bought from a local nursery. The deciduous tree saplings Acer and Fagus were younger than the conifer tree saplings Picea and Abies because of their slower growth rates (Table 1).

\section{Experimental design}

A factorial field experiment involving shade (shade and no shade), mowing of herbaceous vegetation (neighbours and no neighbours), simulated browsing (unclipped and clipped) and species (4, see above) was conducted during two growing seasons (2004-2005). The design followed a split plot design. Six blocks of $14 \times 6 \mathrm{~m}$ were laid out in the sward over three rows. Each block was divided into two plots of each $5 \times 6 \mathrm{~m}$. A plot with shade $\left(\mathrm{S}^{+}\right)$and a plot with no shade $\left(S^{-}\right)$treatment were randomly assigned within each block. The $\mathrm{S}^{+}$plot was spaced $4 \mathrm{~m}$ from the $\mathrm{S}^{-}$plot. Each plot was divided into two sub-plots of $2 \times$ $6 \mathrm{~m}$. A sub-plot with neighbours $\left(\mathrm{N}^{+}\right)$and a sub-plot without neighbours $\left(\mathrm{N}^{-}\right)$were randomly assigned within each plot. Within each sub-plot, 32 saplings (4 species $\times$ 8 repetitions) were randomly transplanted over 11 rows and 3 columns and $0.5 \mathrm{~m}$ spaced from each other. A clipping treatment was randomly assigned to the saplings. A total of 768 saplings were transplanted in early May 2004. Saplings

Table 1. Age, initial height, basal diameter and estimated initial total dry mass (initial DM) (mean \pm SE) of the transplanted tree saplings $(n=192$ per species). Indicated are regression formulas to estimate initial DM from height $(h)$ and basal diameter (d) measures on the four species (with $\mathrm{R}^{2}$ value). For all models, $\mathrm{n}=40$ and $\mathrm{p}<0.001$. Percentage clipped DM (mean \pm SE) was calculated as (clipped $\mathrm{DM}$ )/ (initial DM) of the clipped saplings $(\mathrm{n}=96)$.

\begin{tabular}{|c|c|c|c|c|c|c|c|}
\hline Species & Age (yr) & Height $(\mathrm{cm})$ & Diam (cm) & Regression formulas & $\mathrm{R}^{2}$ & Initial DM (g) & \% clipped \\
\hline Picea & 2 & $12.7 \pm 0.2$ & $0.22 \pm 0.004$ & $1.0572\left(h d^{2}\right)+0.484$ & 0.77 & $1.25 \pm 0.04$ & $32.4 \pm 0.01$ \\
\hline Abies & 3 & $12.9 \pm 0.1$ & $0.24 \pm 0.004$ & $0.9576\left(h d^{2}\right)+0.301$ & 0.75 & $1.05 \pm 0.03$ & $32.2 \pm 0.01$ \\
\hline Acer & 1 & $13.0 \pm 0.3$ & $0.26 \pm 0.003$ & $0.3734\left(h d^{2}\right)+0.078$ & 0.95 & $0.43 \pm 0.02$ & $19.2 \pm 0.01$ \\
\hline Fagus & 1 & $19.2 \pm 0.3$ & $0.35 \pm 0.006$ & $0.3719\left(h d^{2}\right)+0.415$ & 0.84 & $1.39 \pm 0.04$ & $18.4 \pm 0.01$ \\
\hline
\end{tabular}


had been randomized and height and diameter $(1 \mathrm{~cm}$ above root collar) were measured before planting. Forty additional saplings of each species were measured, oven-dried and weighed. These data were used to construct a linear regression model for each species in order to estimate initial total dry mass (DM) of the experimental saplings (Table 1). Saplings that died due to transplantation shock and vole predation before the start of the experiment $(\mathrm{n}=70)$ were replaced in early June 2004.

The shade plot $\left(\mathrm{S}^{+}\right)$consisted of a shade tunnel of $5 \mathrm{~m}$ wide, $6 \mathrm{~m}$ long and $2.4 \mathrm{~m}$ high in the middle and orientated on a north-south axis. A shade cloth (see Fig. 1 for light penetration data) was mounted on a metal frame and draped to $30 \mathrm{~cm}$ from the ground along east and west sides. At the north and south ends of the tunnel an extra shade cloth was mounted and fixed to the soil $2 \mathrm{~m}$ outside the tunnel frame and draped $1 \mathrm{~m}$ from the ground. This allowed us to transplant saplings over the entire length of the shade tunnel because shade was provided in the tunnel even when the position of the sun was low. The shade cloths were installed at the end of June 2004 and removed in late October 2004 before snowfall. They were reinstalled in April 2005, i.e. before the second growing season. In the plots without neighbours $\left(\mathrm{N}^{-}\right)$, aboveground herbaceous vegetation surrounding the saplings was mown to ground level at the end of June 2004 and every four weeks thereafter during the growing season. The plots with neighbours $\left(\mathrm{N}^{+}\right)$and the buffer zone of $1 \mathrm{~m}$ between the $\mathrm{N}^{-}$and $\mathrm{N}^{+}$plots were left intact.

Half of the saplings within each shade $\times$ neighbour combination were clipped using scissors at the same time as the installation of the shade cloths (end of June 2004). The clipping treatment was designed to mimic cattle browsing damage, based on field observations made in the previous year for the same species and sapling stage (Vandenberghe et al. 2007). Hence, we removed less biomass from the deciduous species $(18.4-19.2 \%)$ than

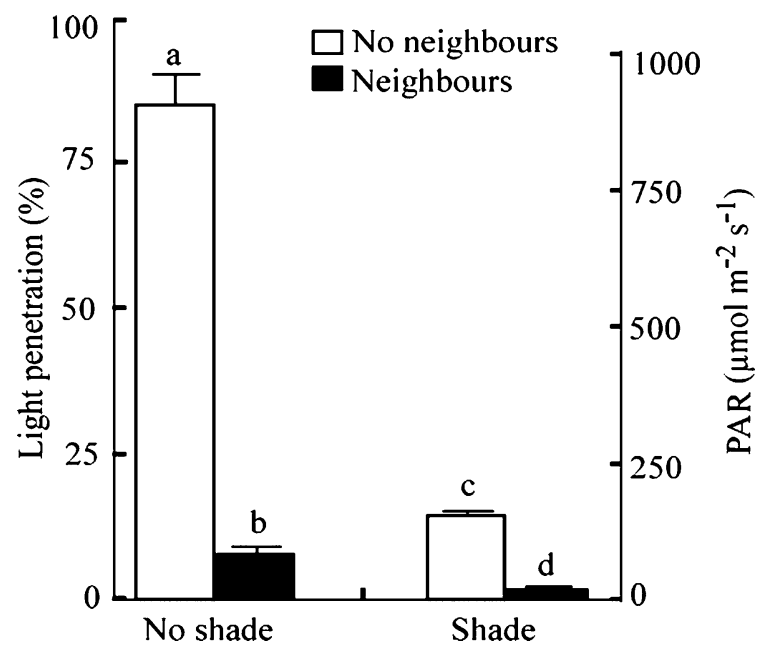

Fig. 1. Impact of shading and neighbour removal on light environment experienced by tree saplings. Presented are means $( \pm 1 \mathrm{SE}, \mathrm{n}=48)$ of light penetration and photosynthetically active radiation at ground level (PAR) in each combination of the two treatments: shade and neighbours. Data were tested with a Kruskal-Wallis test, followed by Mann-Whitney U-tests. Different letters indicate statistically different values $(\mathrm{p}<0.05)$. from the coniferous species (32.2-32.4\%). For the Acer and Fagus saplings we clipped all annual shoots and leaves produced in the current growing season (i.e. defoliation). For Picea and Abies we clipped half of the length of the shoots (with needles) produced during the previous growing season, half of the length of branches larger than $1 \mathrm{~cm}$ and all shoots (with needles) produced in the current growing season. The clipped biomass was oven-dried and weighed and percentage clipped DM was calculated (Table 1).

\section{Measurements}

Photosynthetically active radiation (PAR $\left(\mu \mathrm{mol} \mathrm{m}^{-2} \mathrm{~s}^{-1}\right)$, 400-700 nm) was measured at ground level and at $1 \mathrm{~m}$ above the herbaceous canopy on a sunny day in September 2004 at midday, with two replicates per shade $\times$ neighbour combination in all blocks, using a $\mathrm{Li}-\mathrm{COR}$ radiometer. Light penetration was calculated as \% of incoming light (PAR at ground level $\times$ (above canopy PAR in full light) $\left.)^{-1} \times 100\right)$. Air temperature and humidity and surface soil temperature and moisture were measured during both growing seasons in July and August, by placing one sensor for each variable in each shade $\times$ neighbour combination of one randomly chosen block. All sensors were connected to a Campbell data logger. Measurements were made synchronously at $15-\mathrm{min}$ intervals. Air temperature and humidity sensors were placed $15 \mathrm{~cm}$ above ground level. Surface soil moisture was measured using gypsum blocks. We measured aboveground biomass production (regrowth) of neighbours between $S^{+}$and $S^{-}$, by cutting all aboveground biomass in two $0.25 \mathrm{~m}^{2}$ areas randomly located within all $\mathrm{N}^{-}$plots, four weeks after they were mown (August 2005). Herbaceous biomass was oven-dried and weighed.

Survival was determined in July and September of each growing season. The cause of death was noted as predation when there was an observable damage by voles such as teeth marks on stem, when roots were predated or when the sapling disappeared into a vole gallery exit. Vole predation was a more important cause of death for deciduous than for evergreen saplings with $11 \%$ and $5 \%$ mortality respectively. Saplings that died during the experiment due to predation $(\mathrm{n}=79)$ and accidental mowing $(\mathrm{n}=10)$ were excluded from the dataset. All live saplings $(\mathrm{n}=525)$ were harvested in mid-September 2005 to determine above- and belowground biomass. Roots were extracted from the soil and carefully washed. Saplings were oven-dried and weighed. Overall growth responses were calculated only for live saplings as biomass change $(\mathrm{BC}): \mathrm{BC}=($ final $\mathrm{DM}+$ clipped $\mathrm{DM}) /($ initial DM). Clipped DM was added to the final $\mathrm{DM}$ to more precisely investigate the effect of simulated browsing on plant growth (Belsky 1986). Final survival, expressed as a percentage, and $\mathrm{BC}$ were averaged over the four repetitions for each shade $\times$ neighbour combination per block $(n=6)$. We also calculated the compensatory growth response (CG) of the clipped saplings for each shade $\times$ neighbour combination per block as: $\mathrm{CG}=$ BC_clipped saplings-BC_unclipped saplings (with $C G>0$ : overcompensation; $\mathrm{CG}=0$ : compensation and $\mathrm{CG}<0$ : undercompensation). 


\section{Data analysis}

All statistical analyses were done with $\mathrm{R}$, ver. 2.1.1 (R Foundation for Statistical Computing 2004). Non-parametric Kruskal-Wallis tests and Mann-Whitney U-tests were conducted to analyze the abiotic factors in each shade $\times$ neighbour combination because assumptions for parametric tests were not fulfilled. Regrowth of neighbours was analysed using a one-way Anova.

Shade, neighbour and clipping effects and their interactions on sapling survival were tested with a $\chi^{2}$ likelihood ratio using a logistic regression. A GLM with binomial distribution and logit link function was fitted to the survival data $(n=6)$. The response variable was a two-column matrix representing the number of surviving and dead saplings for each shade $\times$ neighbour combination and species (Venables and Ripley 2002). Because block effects are difficult to interpret in a GLM with categorical data, we did not use mixed-effects models. Block was included as the first explanatory variable in the GLM, which is a hierarchical statistical method, meaning that variables were added sequentially. Blocks were not significant for any of the species, and were omitted from the final model.

A linear mixed-effects split-plot model with residual maximum likelihood estimation (REML, Venables and Ripley 2002) was used to analyze the fixed effects of shade, neighbours and clipping on the means of $\mathrm{BC}$. The response variable $(B C+1)$ was $\log$ transformed to reduce heteroscedasticity. Block was included as a random factor, shade as whole plot factor and neighbours as split plot factor. Overall, $\mathrm{n}=6$ but exceptions occurred due to a lack of surviving saplings at harvest in one or more shade $\times$ neighbour combinations: (1) for Picea, $\mathrm{n}=3$ for $\mathrm{S}^{+} \mathrm{N}^{+}$ combination, $\mathrm{n}=4$ for $\mathrm{S}^{-} \mathrm{N}^{+}$combination and $\mathrm{n}=1$ for $\mathrm{S}^{+} \mathrm{N}^{+}$combination and (2) for Acer, $\mathrm{n}=5$ for $\mathrm{S}^{+} \mathrm{N}^{+}$ combination. CG response was analysed using non-parametric Kruskal-Wallis tests because the assumption for normality was not fulfilled, even after data were transformed. Consequently, we could test for the effects of species, neighbours and shade on CG but not for their interactions.

\section{Results}

\section{Abiotic factors and herbaceous neighbours}

Herbaceous neighbours $\left(\mathrm{N}^{+}\right)$reduced light availability to a greater extent than shade $\left(\mathrm{S}^{+}\right)$with the greatest reduction being when neighbours and shade were present (Fig. 1). Light penetration was significantly different in each shade $x$ neighbour combination $\left(\chi^{2}=43\right.$, DF $\left.3, p<0.0001\right)$. Air and soil temperature were both significantly reduced by shading and neighbours induced an additionally negative effect on soil temperature (Fig. 2; air temp: $\chi^{2}=31$, DF 3 , $\mathrm{p}<0.0001$; soil temp: $\chi^{2}=104$, DF $3, \mathrm{p}<0.0001$ ). Shade and neighbours increased air humidity (Fig. $2 ; \chi^{2}=145$, DF $3, \mathrm{p}<0.0001)$. Surface soil moisture was significantly higher under $\mathrm{S}^{+} \mathrm{N}^{+}$conditions (Fig. 2; $\chi^{2}=8.6$, DF 3, $\mathrm{p}<0.05)$. Shade significantly reduced aboveground biomass production (regrowth in $\mathrm{N}^{-}$) of the neighbouring vegetation by $23 \%(\mathrm{n}=24, \mathrm{~F}=9.9$, DF $1, \mathrm{p}<0.01)$ from a mean $( \pm 1 \mathrm{SE})$ of $165 \pm 10 \mathrm{~g} \mathrm{~m}^{-2}$ in $S^{-}$plots to $127 \pm$ $6 \mathrm{~g} \mathrm{~m}^{-2}$ in $\mathrm{S}^{+}$plots.

\section{Survival}

Mean survival $(\% \pm 1$ SE) was $64 \pm 5.8$ for Picea, $89 \pm 2.6$ for Abies, $78 \pm 3.9$ for Acer and $77 \pm 3.7$ for Fagus (Fig. 3). Clipping reduced Picea, Acer, Fagus and Abies survival by $20 \%, 25 \%, 5 \%$ and $2 \%$ respectively. These reductions were significant for Picea saplings in all cases (Table 2) and for Acer saplings under $\mathrm{S}^{+}$(shade $\times$clipping, Table 2, Fig. 3). Survival was reduced by presence of neighbours for Picea, Abies, Acer and Fagus by 44\%, 5\%, 9\% and 19\% respectively. Sapling survival was positively affected by neighbour removal for Fagus (Table 2) and for Picea and Acer under shade (shade $\times$ neighbours, Table 2, Fig. 3). No significant effects were detected for Abies.

\section{Biomass change and compensatory growth}

The clipping treatment had larger effects under reduced competition from neighbours $\left(\mathrm{N}^{-}\right)$(neighbours $\times$clipping, Table 3). Overall, BC of Picea, Abies, Acer and Fagus
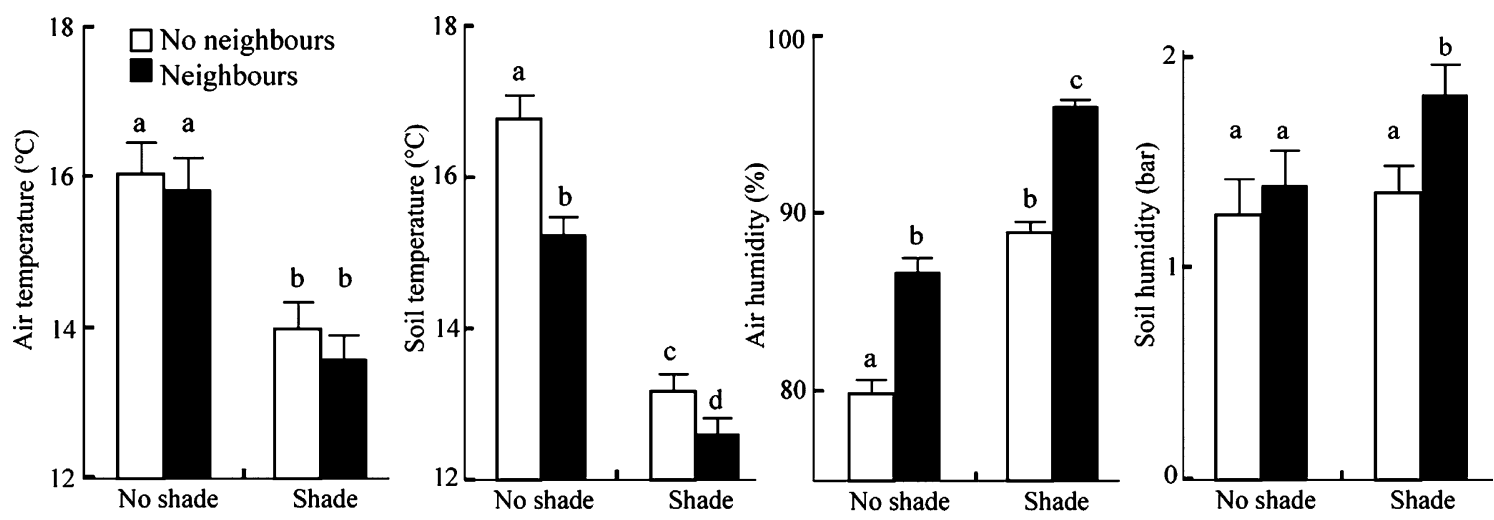

Fig. 2. Effects of shade and neighbour removal treatments on abiotic conditions experienced by tree saplings. Presented are means $( \pm 1$ SE) of abiotic conditions in each shade $\times$ neighbour combination. Data for soil humidity were collected in the growing season of 2004; data of other variables were collected during growing seasons of 2004 and 2005. Data were tested with a Kruskal-Wallis test for each abiotic factor, followed by Mann-Whitney U-tests. Different letters indicate statistically different values $(\mathrm{p}<0.05)$. 

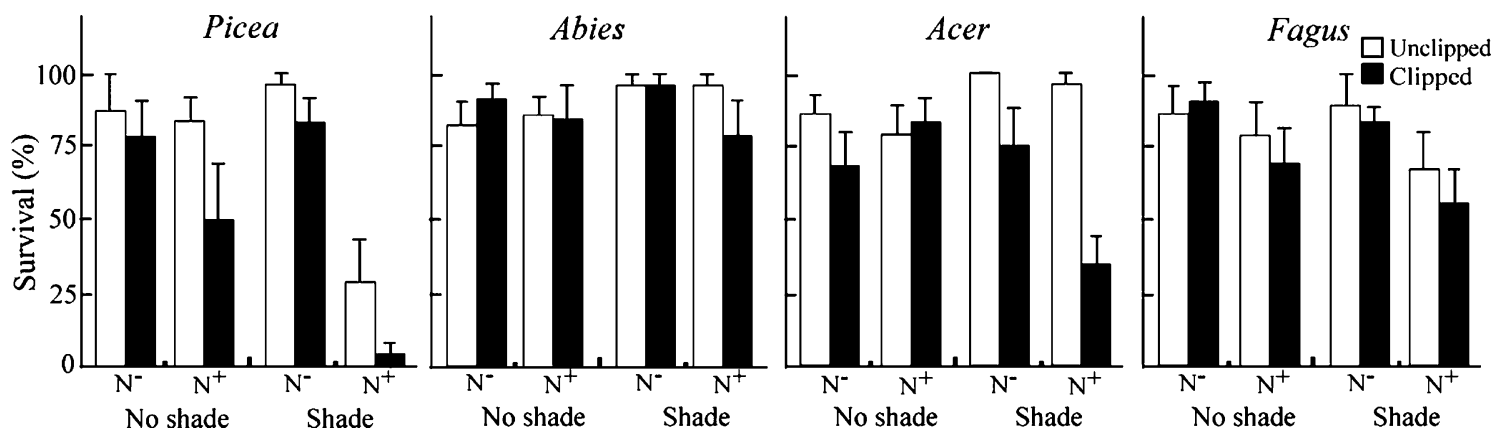

Fig. 3. Effects of simulated browsing (unclipped and clipped), shading and absence $\left(\mathrm{N}^{-}\right)$or presence $\left(\mathrm{N}^{+}\right)$of neighbours on the survival $(\%)$ of saplings of four tree species. Data presented are means ( \pm 1 SE, $n=6$ per treatment).

was reduced by the presence of neighbours by $60 \%, 28 \%$, $56 \%$ and $40 \%$ respectively (Fig. 4). BC of the saplings was influenced positively by shade in $\mathrm{N}^{-}$plots with the exception of Picea (shade $\times$ neighbours, Table 3 ). For Acer, differences between clipped and unclipped saplings were larger under shade with a remarkably large increase in the unclipped saplings in $\mathrm{S}^{+} \mathrm{N}^{-}$plots (shade $\times$clipping, Table 3, Fig. 4).

Saplings were not able to compensate for biomass losses $(\mathrm{CG}<0)$. Only one overcompensation event $(\mathrm{CG}>0)$ was found namely for Picea but this observation was based on $\mathrm{n}=1$. Acer $(-1.82 \pm 0.54)$ and Picea $(-1.74 \pm 0.30)$ had a lower mean CG response than Fagus $(-1.14 \pm 0.28)$ and Abies $(-0.68 \pm 0.13)$ but differences were not significant $\left(\chi^{2}=6.1\right.$, DF $\left.3, p=0.108\right)$. CG response was significantly higher in $\mathrm{N}^{+}$plots $\left(\chi^{2}=39.1\right.$, DF $\left.1, \mathrm{p}<0.001\right)$ but not significantly higher in $S^{+}$plots $\left(\chi^{2}=1.02\right.$, DF $1, \mathrm{p}=$ $0.312)$.

\section{Discussion}

\section{Simulated browsing-environmental interactions}

Plant tolerance is general defined as the ability of plants to maintain fitness through growth and reproduction after experiencing herbivory (Rosenthal and Kotanen 1994, Strauss and Agrawal 1999, Haukioja and Koricheva 2000,
Boege and Marquis 2005). In our experiment, browsing tolerance was never enhanced under low stress conditions, i.e. reduced competition from neighbours, especially under shade. This result contradicts the predictions of the continuum compensatory hypothesis (Belsky et al. 1993, McLaren 1996, Weltzin et al. 1998, Blundell and Peart 2001). Moreover, in most cases, browsing tolerance increased under higher stress conditions, i.e. presence of neighbours under both light and shade. In terms of survival, browsing tolerance of Acer increased under full light, a condition that affected sapling performance of this species more negatively than shade. The effect of the clipping treatment on survival did not vary with shading or competition for the three other species. In terms of growth, browsing tolerance of all species increased in the presence of neighbours and shade tended to strengthen this effect. Reduced competition from neighbours, especially under shade, resulted in higher growth rates but increased also the impacts of clipping. Hence, it is important to distinguish absolute plant growth rates from the relative impact of clipping (Strauss and Agrawal 1999). The increased tolerance under conditions which negatively affected plant performance might be due to the fact that the absolute biomass needed to compensate is smaller (growth rate model of Hilbert et al. 1981, Oesterheld and McNaughton 1991, Hicks and Turkington 2000, Hawkes and Sullivan 2001). However, costs involved with compensatory ability alter with environmental conditions and saplings might

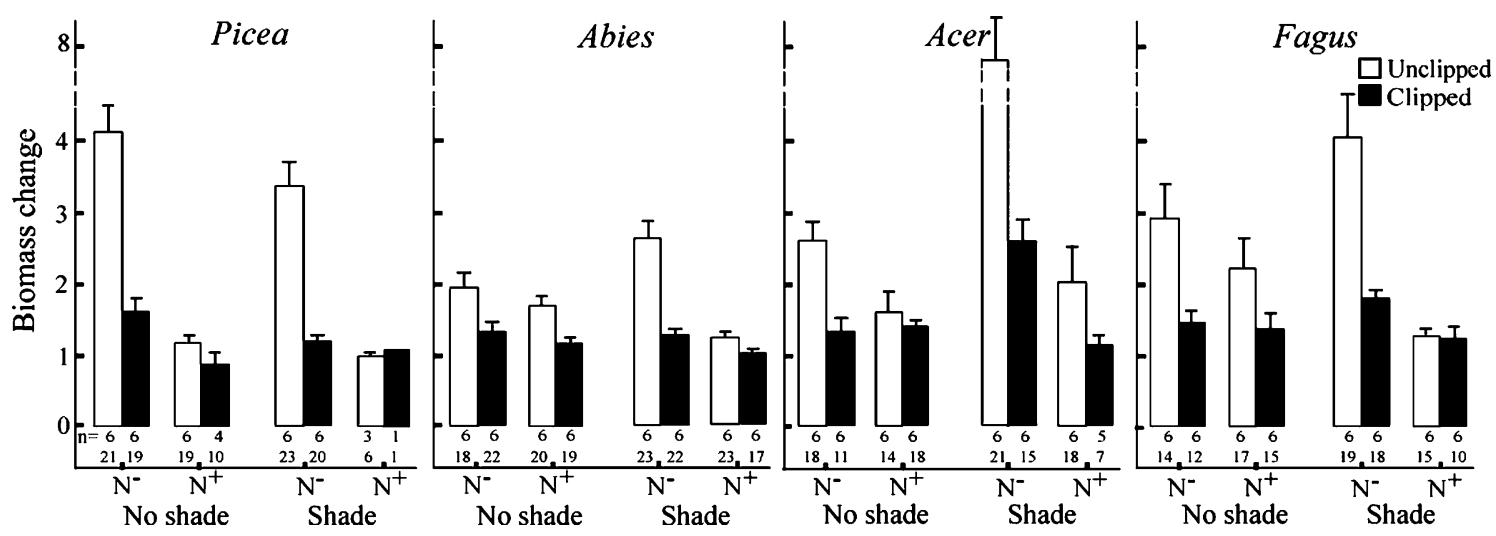

Fig. 4. Effects of simulated browsing (unclipped and clipped), shading and absence $\left(\mathrm{N}^{-}\right)$or presence $\left(\mathrm{N}^{+}\right)$of neighbours on the biomass change $(\mathrm{BC})$ of saplings of four tree species $(\mathrm{BC}>1$ represents an increase in biomass). Data presented are means $( \pm 1$ SE, $n=6$ per treatment when the minimum number of surviving saplings per block $\geq 1$; total number of saplings alive at harvest and used to calculate $\mathrm{BC}$ means are given in the second row (maximum number $=24)$ ). 
Table 2. Results of the logistic regression, using GLM and $\chi^{2}$ likelihood ratios, for the effects of shade, competition from neighbours and clipping and their interactions on the survival of saplings of four tree species $(n=48)$. Saplings that died due to vole predation were excluded from the analysis.

\begin{tabular}{|c|c|c|c|c|c|}
\hline & DF & $\begin{array}{c}\text { Picea } \\
\chi^{2}\end{array}$ & $\begin{array}{c}\text { Abies } \\
\chi^{2}\end{array}$ & $\begin{array}{c}\text { Acer } \\
\chi^{2}\end{array}$ & $\begin{array}{c}\text { Fagus } \\
\chi^{2}\end{array}$ \\
\hline Shade & 1 & $9.1^{* *}$ & $1.0 \mathrm{~ns}$ & $0.26 \mathrm{~ns}$ & $0.9 \mathrm{~ns}$ \\
\hline Neighbours & 1 & $45.9^{* * * *}$ & $1.0 \mathrm{~ns}$ & $2.1 \mathrm{~ns}$ & $8.9^{* *}$ \\
\hline Clipping & 1 & $9.8^{* *}$ & $0.3 \mathrm{~ns}$ & $15.8^{* * * *}$ & $2.7 \mathrm{~ns}$ \\
\hline shade $\times$ neigh & 1 & $14.8^{* * * *}$ & $1.4 \mathrm{~ns}$ & $6.7^{* *}$ & $0.6 \mathrm{~ns}$ \\
\hline shade $\times$ clip & 1 & $0.5 \mathrm{~ns}$ & $2.9 \mathrm{~ns}$ & $10.1^{* *}$ & $0.1 \mathrm{~ns}$ \\
\hline neigh $\times$ clip & 1 & $0.8 \mathrm{~ns}$ & $1.4 \mathrm{~ns}$ & $1.7 \mathrm{~ns}$ & $0.1 \mathrm{~ns}$ \\
\hline sh $\times$ neigh $\times \mathrm{cl}$ & 1 & $0.1 \mathrm{~ns}$ & $0.17 \mathrm{~ns}$ & $0.1 \mathrm{~ns}$ & $0.1 \mathrm{~ns}$ \\
\hline
\end{tabular}

$\mathrm{p}<0.05^{*} ; \mathrm{p}<0.01^{* *} ; \mathrm{p}<0.001^{* * *} ; \mathrm{p}<0.0001^{* * * *} ;$ ns: non-significant result.

have to invest relatively more (e.g. resource allocation from storage) to compensate for smaller absolute biomass losses in stressful, low-nutrient environments (Hochwender et al. 2000). Furthermore, (over)compensation may be more an adaptation for competitive ability rather than herbivory per se as suggested by several authors (Edenius et al. 1993, Hjälten et al. 1993, Puettmann and Saunders 2001, Guillet and Bergström 2006). In the competitive environment, the clipped saplings would thereby concentrate their resources on increasing leader length and biomass production to overtop potential competitors and increase long-term survival chances and fitness. A threshold may exist under which browsing tolerance will be increased by lower stress conditions (McLaren 1996, Blundell and Peart 2001), namely when survival and growth of heavily or repeatedly browsed or defoliated saplings remains very low due to limited resources (e.g. highly limited light availability in forest environment).

\section{Lack of species differences in compensatory growth}

We saw no cases where plants fully compensated for the loss of photosynthetic area and resources (Hawkes and Sullivan 2001, Nykänen and Koricheva 2004). Surprisingly, we did not find significant differences in compensatory growth between species. Deciduous species are considered to have a higher compensatory ability than coniferous species due to a more flexible growth pattern, faster turnover of plant parts and lower substantial loss of energy reserves when being browsed as they store more carbon and nutrients in stem and roots (Bryant et al. 1983, Ayres et al. 2004, Hester et al. 2004). The amount of biomass clipped was lower for the deciduous saplings $(18.8 \%)$ than for the coniferous ones
(32.3\%), giving an even larger potential compensatory growth-advantage to Acer and Fagus according to the carbon/nutrient balance theory (Bryant et al. 1983). Clipping resulted in the complete removal of photosynthetic apparatus from the deciduous saplings, but only partial removal from coniferous saplings. Hence, the sudden large limitation in carbohydrate resource at the beginning of the summer may have led to lower compensation for deciduous species than expected (Guillet and Bergström 2006). Moreover, coniferous saplings ( $2-3$ years) were older than deciduous counterparts (1 year) as planted saplings were selected on size rather than age. This age difference could also account for the lack of compensation differences between deciduous and coniferous saplings as younger saplings cope less well with herbivore damage most likely due to lower stored resources (Nykänen and Koricheva 2004). On the other hand, conifers lost greater proportions of dormant buds, as they are mainly positioned on the shoot tips, whereas deciduous saplings still had most of their dormant buds after clipping, as they are widely positioned on the remaining old wood. Direct comparisons of species growth responses to browsing or clipping are difficult due to differences in plant architecture and nutrient storage sites. Only more precise clipping treatments will further inform our understanding of differences in browsing tolerance between species.

\section{Sapling responses to competition from surrounding neighbours and shade}

In general, the negative effect of herbaceous neighbours on the performance (survival and growth) of the saplings was for all species enhanced under shade. Herbaceous

Table 3. Results of the linear mixed-effects split-plot models with residual maximum likelihood estimation (REML) for the effects of shade, competition from neighbours, clipping and their interactions on biomass change (BC) for saplings of the four tree species.

\begin{tabular}{|c|c|c|c|c|c|c|c|c|}
\hline \multirow{8}{*}{$\begin{array}{l}\text { Shade } \\
\text { Neighbours } \\
\text { Clip } \\
\text { sh } \times \text { neigh } \\
\text { sh } \times \text { clip } \\
\text { neigh } \times \text { clip } \\
\text { sh } \times \text { neigh } \times \text { cl }\end{array}$} & \multicolumn{2}{|c|}{$\begin{array}{c}\text { Picea } \\
\mathrm{n}=38\end{array}$} & \multicolumn{2}{|c|}{$\begin{array}{c}\text { Abies } \\
\mathrm{n}=48\end{array}$} & \multicolumn{2}{|c|}{$\begin{array}{c}\text { Acer } \\
\mathrm{n}=47\end{array}$} & \multicolumn{2}{|c|}{$\begin{array}{c}\text { Fagus } \\
\mathrm{n}=48\end{array}$} \\
\hline & $\mathrm{F}_{1,5}$ & $0.09 \mathrm{~ns}$ & $\mathrm{~F}_{1,5}$ & $0.18 \mathrm{~ns}$ & $\mathrm{~F}_{1,5}$ & $24.2^{* *}$ & $\mathrm{~F}_{1,5}$ & $0.02 \mathrm{~ns}$ \\
\hline & $\mathrm{F}_{1,7}$ & $123^{* * * *}$ & $\mathrm{~F}_{1,10}^{1,5}$ & $23.5^{* * *}$ & $\mathrm{~F}_{1,10}$ & $42.7^{* * *}$ & $\mathrm{~F}_{1,10}$ & $29.5^{* * *}$ \\
\hline & $F_{1,13}$ & $106^{* * * * *}$ & $\mathrm{~F}_{1,20}$ & $58.0 * * * *$ & $\mathrm{~F}_{1,19}$ & $33.9 * * * *$ & $\mathrm{~F}_{1,20}$ & $31.9^{* * * *}$ \\
\hline & $\mathrm{F}_{1,7}$ & $0.27 \mathrm{~ns}$ & $F_{1,10}$ & $8.38^{*}$ & $F_{1,10}$ & $20.9 * *$ & $F_{1,10}$ & $10.4^{* *}$ \\
\hline & $\mathrm{F}_{1,13}$ & $1.37 \mathrm{~ns}$ & $\mathrm{~F}_{1,20}$ & $0.79 \mathrm{~ns}$ & $F_{1,19}$ & $6.14^{*}$ & $F_{1,20}$ & $0.41 \mathrm{~ns}$ \\
\hline & $F_{1,13}$ & $33.8^{* * *}$ & $\mathrm{~F}_{1,20}$ & $7.60^{*}$ & $\mathrm{~F}_{1,19}$ & $12.3^{* *}$ & $\mathrm{~F}_{1,20}$ & $9.25^{* *}$ \\
\hline & $F_{1,13}$ & $0.53 \mathrm{~ns}$ & $F_{1,20}$ & $7.75^{*}$ & $F_{1,19}$ & $0.47 \mathrm{~ns}$ & $F_{1,20}$ & $2.25 \mathrm{~ns}$ \\
\hline
\end{tabular}

$\mathrm{p}<0.05^{*} ; \mathrm{p}<0.01^{* *} ; \mathrm{p}<0.001^{* * *} ; \mathrm{p}<0.0001^{* * * *}$ ns: non-significant result. 
neighbours reduced light availability more than did shade nets, making light a highly contested resource under the combination of both treatments $\left(\mathrm{S}^{+} \mathrm{N}^{+}\right)$. Overgrowth by neighbours implied not only a light reduction but probably also a significant decrease in space (Husheer et al. 2006, Vandenberge unpubl.) and nutrient availability (Wilson 1998). Picea was the least competition tolerant tree species (Pagès et al. 2003, Heuze et al. 2005), and the effect of competition from neighbours was greater than any direct negative effect of biomass removal per se as found by Prach et al. (1996). Furthermore, the low competition tolerance of Picea rather than its intrinsic (i.e. physiological and morphological) tolerance features is most likely cause of the negative effect of clipping on survival.

Full sun conditions were not required for maximum performance in the juvenile tree stage. Shade increased growth of Abies, Acer and Fagus saplings when surrounding vegetation was mown. One mechanism explaining this could be reduced photoinhibition. Strong irradiance, as found in open pastures, can lead to a decline in photosynthetic efficiency, especially for shade-tolerant species, due to damage of the photosynthetic apparatus (Long et al. 1994, Alves et al. 2002). Light availability in the shaded and mown plots $\left(\mathrm{S}^{+} \mathrm{N}^{-}\right)$corresponded approximately with large forest gaps of $250 \mathrm{~m}^{2}$ (in Sipe and Bazzaz 1995) and might not be considered a limited resource for sapling growth. Furthermore, increased air humidity and reduced temperature under shade will generate reduced rates of transpiration. As a result plants are likely to have maintained a larger stomatal aperture resulting in enhanced photosynthetic rates (Holmgren 2000). The maximal growth of Picea in full light plots without neighbours $\left(\mathrm{S}^{-} \mathrm{N}^{-}\right)$might be due to their more efficient photoprotective system (McKinnon and Mitchell 2003). Indirect facilitation could also have enhanced growth in shaded plots without neighbours, i.e. shade having an indirect positive effect on sapling performance through biomass reduction of the competing surrounding vegetation (Levine 1999, Siemann and Rogers 2003). Under shade, growth of herbaceous vegetation was reduced by approximately $23 \%$ and this could have been sufficient to reduce belowground competition and enhance nitrogen availability. It was suggested by Pagès et al. (2003) that shade-intolerant conservative (i.e. relative slow growth responses to increased nutrient availability) tree species such as Picea are poor candidates for positive indirect interactions. Conversely, Acer has the essential traits for indirect facilitation, in its ability to respond quickly to increased nutrient availability. Both mechanisms might explain the remarkable positive effects of shade on Acer saplings and consequent significant clipping-shade interactions for this species.

\section{Ecological implications for wood-pastures}

Plant resistance to browsing is not only defined by tolerance, but also by escape and chemical or physical defence (Haukioja and Koricheva 2000, Boege and Marquis 2005). In the wood-pastures of the Swiss Jura Mountains, none of the four co-dominant tree species is avoided by cattle and the probability for the species of being browsed is equal (Vandenberghe et al. 2007, Smit et al. 2007). However, repeated browsing events and variation among species in the amounts of tissue lost per browsing event (due to differences in plant architecture or chemical composition; Tripler et al. 2002, Vandenberghe et al. 2007) might cause differences in sapling responses to cattle browsing in natural situations when compared to the outcome of this experiment. Nonetheless, this study provides new insight into the tolerance of four naturally co-occurring tree species to herbivory since browsing tolerance was enhanced under conditions that negatively affected sapling performance. The relative importance of browsing impacts depended on the adaptation of tree saplings to their environmental conditions. Our results could prove useful when evaluating management schemes, and conservation and restoration policies at the level of temperate wood-pasture ecosystems, as illustrated by the following examples: 1) the impact of browsing will be relatively lower under situations with intense competitive interactions between neighbours and tree saplings, e.g. under low grazing intensities (Bakker 1998), especially for low competition tolerant species (e.g. Picea). 2) The impact of browsing will be relatively lower under full sun conditions, e.g. in open pastures, especially for tree species which are sensitive to strong irradiance or hold traits for indirect facilitation by shade (e.g. Acer). 3) The high simulated browsing tolerance of Abies in our study was rather surprising (Ammer 1996, Ayres et al. 2004). Impacts of browsing on silver fir sapling survival have rarely been directly measured and the frequent observed failure of fir regeneration is probably more related to higher consumption rates by herbivores or inter-tree competition at later stages than to a relatively low tolerance for browsing (Senn and Suter 2003, Heuze et al. 2005). Further insight in the browsing resistance of co-occurring tree species in wood-pastures at all life stages and other factors such as seed availability, seed dispersal and seedling emergence is needed to inform the conservation and restoration of this complex, endangered wood-pasture system. In our study system, the relative impact of browsing at the early sapling stage is linked to tree life history characteristics such as competition and shade tolerance and tends to be lower in situations with intense competitive interactions and/or strong irradiance.

Acknowledgements - We thank Agroscope Changins-Wädenswil (ACW) for the access at La Frétaz and for providing material. We thank M. Pohl, S. Attinger, W. Herren, E. Rossel, L. Freléchoux, M. Wells and A. Carnelli for their assistance in the field. We thank J. Millett, J. P. Pagès, G. Prior and N. Littlewood for helpful comments on the manuscript. This study was financially supported by MAVA Foundation and the Swiss Federal Research Institute WSL (programme Walddynamik, T. Wohlgemuth).

\section{References}

Alves, P. L. C. A. et al. 2002. The phenomenon of photoinhibition of photosynthesis and its importance in reforestation. - Bot. Rev. 68: 193-208.

Ammer, C. 1996. Impact of ungulates on structure and dynamics of natural regeneration of mixed mountain forests in the Bavarian Alps. - For. Ecol. Manage. 88: 43-53.

Ayres, E. et al. 2004. Tree physiological responses to above-ground herbivory directly modify below-ground processes of soil carbon and nitrogen cycling. - Ecol. Lett. 7: 469-479. 
Bakker, E. S. et al. 2004. Ecological anachronisms in the recruitment of temperate light-demanding tree species in wooded pastures. - J. Appl. Ecol. 41: 571-582.

Bakker, J. P. 1998. The impact of grazing on plant communities. - In: WallisDeVries, M. F. et al. (eds), Grazing and conservation management. Kluwer Academic, pp. 137-184.

Belsky, A. J. 1986. Does herbivory benefit plants-a review of the evidence. - Am. Nat. 127: 870-892.

Belsky, A. J. et al. 1993. Overcompensation by plants-herbivore optimization or red herring. - Evol. Ecol. 7: 109-121.

Blundell, A. G. and Peart, D. R. 2001. Growth strategies of a shade-tolerant tropical tree: the interactive effects of canopy gaps and simulated herbivory. - J. Ecol. 89: 608-615.

Boege, K. and Marquis, R. J. 2005. Facing herbivory as you grow up: the ontogeny of resistance in plants. - Trends Ecol. Evol. 20: 441-448.

Breziecki, B. and Kienast, F. 1984. Classifying the life history strategies of trees on the basis of the Grimian model. - For. Ecol. Manage. 69: 167-187.

Bryant, J. P. et al. 1983. Carbon/nutrient balance of boreal plant in relation to vertebrate herbivory. - Oikos 40: 357-368.

Callaway, R. M. 1992. Morphological and physiological responses of 3 California oak species to shade. - Int. J. Plant Sci. 153: 434-441.

Edenius, L. et al. 1993. Impact of herbivory and competition on compensatory growth in woody plants: winter browsing by moose on Scots pine. - Oikos 66: 286-292.

Etienne, M. 1996. Research on temperate and tropical silvopastural sytems: a review. - In: Etienne, M. (ed.), Western European silvopastural systems. INRA, Paris, pp. 5-19.

Gill, D. S. and Marks, P. L. 1991. Tree and shrub seedling colonization of old fields in central New York. - Ecol. Monogr. 61: 183-205.

Guillet, C. and Bergström, R. 2006. Compensatory growth of fastgrowing willow (Salix) coppice in response to simulated large herbivore browsing. - Oikos 113: 33-42.

Haukioja, E. and Koricheva, J. 2000. Tolerance to herbivory in woody versus herbaceous plants. - Evol. Ecol. 14: 551-562.

Hawkes, C. V. and Sullivan, J. J. 2001. The impact of herbivory on plants in different resource conditions: a meta-analysis. - Ecology 82: 2045-2058.

Hester, A. J. et al. 2004. How does timing of browsing affect above- and below-ground growth of Betula pendula, Pinus sylvestris and Sorbus aucuparia? - Oikos 105: 536-550.

Heuze, P. et al. 2005. Is browsing the major factor of silver fir decline in the Vosges Mountains of France? - For. Ecol. Manage. 217: 219-228.

Hicks, S. and Turkington, R. 2000. Compensatory growth of three herbaceous perennial species: the effects of clipping and nutrient availability. - Can. J. Bot. 78: 759-767.

Hilbert, D. W. et al. 1981. Relative growth-rates and the grazing optimization hypothesis. - Oecologia 51: 14-18.

Hjälten, J. et al. 1993. Effects of simulated herbivory and intraspecific competition on the compensatory ability of birches. - Ecology 74: 1136-1142.

Hochwender, C. G. et al. 2000. The potential for and constraints on the evolution of compensatory ability in Asclepias syriaca. - Oecolgia 122: 361-370.

Holmgren, M. 2000. Combined effects of shade and drought on tulip poplar seedlings: tradeoff in tolerance or facilitation? - Oikos 90: 67-78.

House, J. I. et al. 2003. Conundrums in mixed woody-herbaceous plant systems. - J. Biogeogr. 30: 1763-1777.

Husheer, S. W. et al. 2006. Herbivory and plant competition reduce mountain beech seedling growth. - Plant Ecol. 183: 245-256.

Kozlowski, T. T. and Pallardy, S. G. 1997. Growth control in woody plants. - Academic Press.
Lauber, K. and Wagner, G. 2000. Flora Helvetica, flore illustrée de Suisse. - Haupt., Berne.

Levine, J. M. 1999. Indirect facilitation: evidence and predictions from a riparian community. - Ecology 80: 1762-1769.

Liang, S. Y. and Seagle, S. W. 2002. Browsing and microhabitat effects on riparian forest woody seedling demography. - Ecology 83: 212-227.

Long, S. P. et al. 1994. Photoinhibition of photosynthesis in nature. - Annu. Rev. Plant Phys. 45: 633-662.

McKinnon, L. M. and Mitchell, A. K. 2003. Photoprotection, not increased growth, characterizes the response of Engelmann spruce (Picea engelmannii) seedlings to high light, even when resources are plentiful. - New Phytol. 160: 69-79.

McLaren, B. E. 1996. Plant-specific response to herbivory: simulated browsing of suppressed Balsam fir on Isle Royale. - Ecology 77: 228-235.

Nykänen, H. and Koricheva, J. 2004. Damage-induced changes in woody plants and their effects on insect herbivore performance: a meta-analysis. - Oikos 104: 247-268.

Olff, H. et al. 1999. Shifting mosaics in grazed woodlands driven by the alternation of plant facilitation and competition. - Plant Biol. 1: 127-137.

Oesterheld, M. and McNaughton, S. J. 1991. Effect of stress and time for recovery on the amount of compensatory growth after grazing. - Oecologia 85: 305-313.

Pagès, J. P. et al. 2003. Direct and indirect effects of shade on four forest tree seedlings in the French Alps. - Ecology 84: 2741-2750.

Peltzer, D. A. and Köchy, M. 2001. Competitive effects of grasses and woody plants in mixed-grass prairie. - J. Ecol. 89: 519-527.

Pott, R. and Hüppe, J. 1991. Die Hudelandschaften Nordwestdeutschlands. Landschaftsverband Westfalen-Lippe, Veröfftentlichung der Arbeitsgemeinschaft für biologisch-ökologische Landeserforschung, ABOL, no. 89, - Westfälisches Museum für Naturkunde, Münster.

Prach, K. et al. 1996. Establishment of Picea abies seedlings in a central European mountain grassland: an experimental study. - J. Veg. Sci. 7: 681-684.

Puettmann, K. J. and Saunders, M. R. 2001. Patterns of growth compensation in eastern white pine (Pinus strobus L.): the influence of herbivory intensity and competitive environments. - Oecologia 129: 376-384.

Rosenthal, J. P. and Kotanen, P. M. 1994. Terrestrial plant tolerance to herbivory. - Trends Ecol. Evol. 9: 145-148.

Senn, J. and Suter, W. 2003. Ungulate browsing on silver fir (Abies alba) in the Swiss Alps: beliefs in search of supporting data. - For. Ecol. Manage. 181: 151-164.

Siemann, E. and Rogers, W. E. 2003. Changes in light and nitrogen availability under pioneer trees may indirectly facilitate tree invasions of grasslands. - J. Ecol. 91: 923-931.

Sipe, T. W. and Bazzaz, F. A. 1995. Gap partitioning among maples (Acer) in central New England: survival and growth. - Ecology 76: 1587-1602.

Smit, C. et al. 2006. Unpalatable plants facilitate tree sapling survival in wood pastures. - J. Appl. Ecol. 43: 305-312.

Smit, C. et al. 2007. Nurse plants, tree saplings and grazing pressure: changes in facilitation along a biotic environmental gradient. - Oecologia. 152: 265-273.

Strauss, S. Y. and Agrawal, A. A. 1999. The ecology and evolution of plant tolerance to herbivory. - Trends Ecol. Evol. 14: 179185.

Tripler, C. E. et al. 2002. Soil nitrogen availability, plant luxury consumption, and herbivory by white-tailed deer. - Oecologia 133: $517-524$.

Vandenberghe, C. et al. 2007. Short-term effects of cattle grazing on tree sapling growth in mountain wooded pastures. - Plant Ecol. 188: 253-264. 
Venables, W. N. and Ripley, B. D. 2002. Modern applied statistics with $S$, 4th ed. - Springer.

Vera, F. W. M. 2000. Grazing ecology and forest history. - CABI Publishing.

Weltzin, J. E. et al. 1998. Defoliation and woody plant (Prosopis glandulosa) seedling regeneration: potential vs realized herbivory tolerance. - Plant Ecol. 138: 127-135.
Wilson, S. D. 1998. Competition between grasses and woody species. - In: Cheplick, G. P. (ed.), Population biology of grasses. Cambridge Univ. Press, pp. 231-254.

Wise, M. J. and Abrahamson, W. G. 2005. Beyond the compensatory continuum: environmental resource levels and plant tolerance of herbivory. - Oikos 109: 417-428. 